Research Article

\title{
Characterization of Integrons and Antimicrobial Resistance in Escherichia coli Sequence Type 131 Isolates
}

\author{
Jiangqing Huang, Fangjun Lan, Yanfang Lu, and Bin Li (iD \\ Department of Clinical Laboratory, Fujian Medical University Union Hospital, Fuzhou, Fujian 350001, China \\ Correspondence should be addressed to Bin Li; leonlee307@hotmail.com
}

Received 30 September 2019; Revised 5 January 2020; Accepted 14 January 2020; Published 24 February 2020

Academic Editor: Bruno Pozzetto

Copyright (C) 2020 Jiangqing Huang et al. This is an open access article distributed under the Creative Commons Attribution License, which permits unrestricted use, distribution, and reproduction in any medium, provided the original work is properly cited.

\begin{abstract}
Background. Escherichia coli sequence type 131 (ST131) is an important multidrug-resistant extraintestinal pathogen, which can cause many kinds of infections. Integrons may play a crucial role in the dissemination of antibiotic resistance genes. The purpose of this study was to characterize the prevelance of integrons among E. coli ST131 strains in China. Methods. Eighty-three E. coli ST131 isolates were used in this study. The antibiotic susceptibility test was performed by the disk diffusion method. The presence and characterization of class 1,2, and 3 integrons, as well as promotor of gene cassettes and other antimicrobial resistance genes, were detected by PCR and DNA sequencing. Transfer of integrons was carried out using a broth culture mating method. Clonal relatedness of $E$. coli ST131 isolates was analyzed by PFGE. Results. Overall, 26.5\% (22/83) of the E. coli ST131 isolates carried class 1 integrons. Class 2 and 3 integrons were not found in this study. Two types of gene cassette arrays were demonstrated in this study and were as follows: $d f r A 17-a a d A 5$ and $a a c\left(6^{\prime}\right)-I b-c r-c m l A 5$. Only one type of Pc promoter variant was detected among 22 integron-positive isolates $(\mathrm{PcW})$. In vivo transfer of integron was successful for 9 of integron-positive E. coli ST131 isolates harboring resistance gene cassettes. Results of PFGE demonstrated that the integron-positive E. coli ST131 isolates were grouped into 12 different PFGE clusters. Conclusions. Our study showed a low prevalence of integrons was detected in E. coli ST131. Continued surveillance of this mobile genetic element should be performed to study the evolution of antibiotic resistance among E. coli ST131.
\end{abstract}

\section{Introduction}

Integrons are genetic elements found in bacteria, which can capture and express antimicrobial resistance gene cassettes [1]. Integrons are strongly associated with the dissemination of antimicrobial genes among different genera of bacteria [2]. Several types of integron classes have been found nowadays in bacteria [3]. Integrons are often located on transmissible plasmids or transposons, which can facilitate the transferability of antimicrobial genes among bacteria [4].

Escherichia coli sequence type 131 (E. coli ST131) is an important multidrug-resistant extraintestinal pathogen. It is firstly identified in 2008 and now disseminated globally [5]. E. coli ST131 is becoming the predominant extraintestinal pathogenic E. coli lineage and can cause many clinical infections, such as sepsis and urinary tract infections [6]. E. coli ST131 are usually reported to produce extended spectrum $\beta$-lactamases and show resistance to fluoroquinones $[7,8]$. The emergence of such pathogen has made a significant contribution to the rising prevalence of antibiotic resistance [9].

Integrons, especially class 1 and 2 ones, have a worldwide distribution in Enterobacteriaceae [10,11]. This has led to the speculation that integrons probably involve in the dissemination of antimicrobial resistance genes in E. coli ST131. Thus, in this study, we determined the distribution of various integrons among E. coli ST131 collected at a university hospital in southern China.

\section{Materials and Methods}

2.1. Bacterial Isolates. A total of 83 E. coli ST131 were used in this study, which were collected at a Chinese university hospital (Fujian Medical University Union Hospital, 
Fuzhou, Fujian province, China) between August 2014 and August 2015. These strains were isolated and reported in our previous study [8].

2.2. Antimicrobial Susceptibility Testing. The antimicrobial sensitivity was tested by the disk diffusion method according to the Clinical and Laboratory Standards Institute (CLSI, 2016) guidelines [12]. The antibiotics used for the susceptibility tests were cefotaxime (CTX), ceftazidime (CAZ), cefepime (FEP), ciprofloxacin (CIP), levofloxacin (LEV), amikacin (AMK), imipenem (IMP), piperacillin-tazobactam (TZP), aztreonam (ATM), trimethoprim-sulfamethoxazole (SXT), and ertapenem (ETP). E. coli ATCC 25922 was used for quality control.

\subsection{Detection of Integrons, Their Pc Promoters, and Associated} Resistance Genes. The presence of class 1, 2, and 3 integrons was analyzed by PCR in E. coli ST131 as described previously [13]. The characterization of the variable region of integrons was detected by PCR and DNA sequencing. In those isolates that were positive for intI1, the Pc promotor region was detected as described previously [14].

The presence of genes associated with ampicillin (blaTEM, blaSHV, and blaOXA-1), tetracycline (tetA-tetE), streptomycin (aadA), sulphonamide (sul1, sul2, and sul3), kanamycin (aphA1 and aphA2), chloramphenicol resistance ( $\mathrm{cmlA}$ and $f l o R)$, and plasmid-borne quinolone resistance genes ( $q n r A, q n r B$, and $q n r S)$ was also analyzed by PCR $[13,15]$.

2.4. Conjugation Experiments and Plasmids Detection. A conjugation experiment was performed in broth culture with E. coli J53 $A z^{r}$ as the recipient [16]. Conjugation experiments were carried out with integron-positive strains harboring resistance gene cassettes. Transconjugants were selected on MacConkey agar plates containing streptomycin at $50 \mathrm{mg} / \mathrm{liter}$ and sodium azide at $100 \mathrm{mg} / \mathrm{liter}$ for selection. The grown isolates were selected and identified by the Vitek system.

2.5. Pulsed-Field Gel Electrophoresis Analysis (PFGE). The integron-positive E. coli ST131 isolates were subjected to molecular typing using XbaI digestion by pulsed-field gel electrophoresis, which clonally evaluates isolates. A PFGE dendrogram was constructed with BioNumerics software (Applied Maths, Sint-Martens-Latem, Belgium) according to the unweighted pair group method based on Dice coefficients. Isolates with a Dice similarity index $\geq 70 \%$ were considered to belong to the same PFGE cluster [17].

2.6. Statistical Analysis. SPSS22.0 statistical software was used for statistical analysis, and the chi-square test or Fisher's exact test (two tailed) or Mann-Whitney test was performed for data comparison. Only $p<0.05$ was considered statistically significant.

\section{Results}

3.1. Integrons, Pc Promoters, and Associated Resistance Genes. Of the 83 E. coli ST131 isolates, 22 (27\%) carried class 1 integrons. Class 2 and class 3 integrons were not detected in the study. The clinical characteristics of E. coli ST131 are showed in Table 1 . The result of serotype revealed the integron-positive E. coli ST131 belonged to two types, and the most prevalence type was O25b (77.3\%, 17/22). Results of phylogenetic analysis showed that 21/22 (95.5\%) of isolates belonged to group B2 and 1/22 (4.5\%) were D group. Several types of fragments ranging in size from $0.15 \mathrm{~kb}$ to $3.0 \mathrm{~kb}$ were identified (Table 2). Sixteen isolates carried a single integron with a same gene cassette ( $d$ frA17-aadA5). Two gene cassette arrangements were detected in 19 (86.4\%) of integron-positive isolates. In addition, only one isolate carried the $a a c\left(6^{\prime}\right)-I b-c r-c m l A 5$ gene cassette array with the largest size $(3.0 \mathrm{~kb})$. In this study, only one Pc variant $(\mathrm{PcW})$ was found in 22 integron-positive E. coli ST131, as shown in Table 1.

Table 3 shows the antimicrobial resistance genes detected in our E. coli ST131 isolates. The blaTEM gene was predominant in integron-positve E. coli ST131 isolates, and the blaOXA-1 gene was in 9 isolates. The blaSHV gene was not found in this study. Regarding tetracycline resistance, tet $A+$ tet $C$ was more common in those strains with integron than those strains without integron. The following genes were detected among 56 SXT-resistant isolates (integronpositive/integron-negative isolates): sul1 (15/7), sul2 (2/5), and sul $1+$ sul $2(3 / 20)$. Among the 16 ciprofloxacin-resistant integron-positive isolates, the $q n r B$ gene was detected in 2 isolates. Among the 22 integron-positive E. coli ST131 isolates, the $\operatorname{clm} A$ gene and $\operatorname{clm} A+$ floR gene were found in two different isolates. The aadA gene was observed in two of 22 integron-positive isolates, and none of these isolates carried $a p h A 1$ and aphA2 gene which conferred kanamycin resistance.

3.2. Antimicrobial Susceptibility Testing. E. coli ST131 showed high resistance to CTX (71.1\%), CIP (69.9\%), LEV (69.9\%), and SXT (67.5\%). However, resistance rates were low to ATM (36.1\%), FEP (31.3\%), CAZ (26.5\%), AK (8.4\%), IPM (3.6\%), and TZP (1.2\%). None of the isolates were resistant to ETP. The results of the antimicrobial susceptibility test were shown in Table 4 . Compared with integron-negative E.coli ST131, integron-positive ones were shown to have a higher resistance to SXT and FEP $(p<0.05$, respectively). Multidrug resistance (defined as resistance to six or more antibiotics) rates of integron-positive and -negative E.coli ST131 isolates were $45.5 \%$ and $18.0 \%$, respectively.

3.3. Conjugation Experiments. In this study, transfer of integrons was successful in 9 of 17 integron-positive E. coli ST131 isolates harboring resistance gene cassettes (Table 1). The presence of integrons in the transconjugants was confirmed by PCR. 
TABLE 1: Phenotypic and genotypic characteristics of 22 integron-positive E. coli ST131 isolates.

\begin{tabular}{|c|c|c|c|c|c|c|c|c|c|c|}
\hline \multirow{2}{*}{ Isolates } & \multirow{2}{*}{ Ward } & \multirow{2}{*}{ Source } & \multirow{2}{*}{ Age } & \multirow{2}{*}{ Sex } & \multicolumn{2}{|c|}{$\begin{array}{l}\text { Genetic material in } \\
\text { isolate with integron }\end{array}$} & \multirow{2}{*}{ Serotype } & \multirow{2}{*}{$\begin{array}{l}\text { Phylogenetic } \\
\text { group }\end{array}$} & \multirow{2}{*}{$\begin{array}{l}\text { Resistance } \\
\text { proflies }\end{array}$} & \multirow{2}{*}{$\begin{array}{l}\text { Conjugation } \\
\text { experiments }\end{array}$} \\
\hline & & & & & Promoter & $\begin{array}{c}\text { Gene } \\
\text { cassette }(\mathrm{s})\end{array}$ & & & & \\
\hline EC327 & Urinary surgery & Urine & 48 & $\mathrm{~F}$ & $\mathrm{PcW}$ & $-{ }^{1}$ & $\mathrm{O} 25 \mathrm{~b}$ & B2 & SXT & \\
\hline EC431 & $\begin{array}{l}\text { Emergency } \\
\text { surgery }\end{array}$ & Drain & 78 & $\mathrm{~F}$ & $\mathrm{PcW}$ & - & $\mathrm{O} 16$ & B2 & $\begin{array}{c}\text { CTX, CAZ, FEP, } \\
\text { CI } \\
\text { P, LEV, ATM, } \\
\text { SXT } \\
\text { CTX, CIP, LEV, } \\
\text { SXT }\end{array}$ & \\
\hline EC455 & $\begin{array}{l}\text { Colorectal } \\
\text { surgery }\end{array}$ & Drain & 62 & $\mathrm{~F}$ & $\mathrm{PcW}$ & $\begin{array}{l}\text { dfrA17- } \\
\text { aadA5 }\end{array}$ & $\mathrm{O} 16$ & B2 & & $+^{2}$ \\
\hline EC485 & Urinary surgery & Urine & 60 & $\mathrm{M}$ & $\mathrm{PcW}$ & $\begin{array}{c}a a c\left(6^{\prime}\right)-I b- \\
c r-c m l A 5 \\
\end{array}$ & $\mathrm{O} 16$ & B2 & - & \\
\hline EC541 & Neurosurgery & Blood & 69 & $\mathrm{M}$ & PcW & $\begin{array}{l}\text { dfrA17- } \\
\text { aadA5 }\end{array}$ & $\mathrm{O} 25 \mathrm{~b}$ & B2 & CTX, SXT & \\
\hline EC549 & Neurosurgery & Urine & 39 & $\mathrm{~F}$ & $\mathrm{PcW}$ & $\begin{array}{l}\text { dfrA17- } \\
\operatorname{aadA5}\end{array}$ & $\mathrm{O} 25 \mathrm{~b}$ & B2 & $\begin{array}{l}\text { CTX, CAZ, FEP, } \\
\text { CIP, LEV, AMK, } \\
\text { ATM, SXT }\end{array}$ & \\
\hline EC568 & $\begin{array}{l}\text { Hepatobiliary } \\
\text { surgery }\end{array}$ & Blood & 75 & $\mathrm{M}$ & PcW & $\begin{array}{l}d f r A 17- \\
\operatorname{aadA5}\end{array}$ & $\mathrm{O} 25 \mathrm{~b}$ & B2 & $\begin{array}{c}\text { CTX, CAZ, FEP, } \\
\text { CIP, LEV, AMK, } \\
\text { ATM, SXT }\end{array}$ & \\
\hline EC570 & Urinary surgery & Urine & 51 & $\mathrm{~F}$ & $\mathrm{PcW}$ & $\begin{array}{l}d f r A 17- \\
\text { aadA5 }\end{array}$ & $\mathrm{O} 25 \mathrm{~b}$ & B2 & $\begin{array}{c}\text { CTX, FEP, CIP, } \\
\text { LEV, AMK, } \\
\text { ATM, SXT }\end{array}$ & \\
\hline EC578 & Urinary surgery & Urine & 68 & $\mathrm{M}$ & PcW & $\begin{array}{l}d f r A 17- \\
\text { aadA5 }\end{array}$ & $\mathrm{O} 16$ & $\mathrm{D}$ & $\begin{array}{l}\text { CTX, FEP, CIP, } \\
\text { LEV, SXT }\end{array}$ & + \\
\hline EC668 & Oncology & Urine & 59 & $\mathrm{~F}$ & $\mathrm{PcW}$ & $\begin{array}{l}\text { dfrA17- } \\
\text { aadA5 }\end{array}$ & $\mathrm{O} 25 \mathrm{~b}$ & B2 & $\begin{array}{l}\text { CTX, CIP, LEV, } \\
\text { SXT }\end{array}$ & + \\
\hline EC686 & Cardiology & Urine & 78 & $\mathrm{M}$ & $\mathrm{PcW}$ & $\begin{array}{l}d f r A 17- \\
\text { aadA5 }\end{array}$ & $\mathrm{O} 16$ & B2 & CIP, LEV, SXT & + \\
\hline EC771 & Outpatient & Blood & 61 & $\mathrm{~F}$ & $\mathrm{PcW}$ & - & $\mathrm{O} 25 \mathrm{~b}$ & B2 & SXT & \\
\hline EC786 & Nephrology & Blood & 64 & $\mathrm{~F}$ & $\mathrm{PcW}$ & $\begin{array}{l}d f r A 17- \\
\text { aadA5 }\end{array}$ & $\mathrm{O} 25 \mathrm{~b}$ & B2 & $\begin{array}{c}\text { CTX, CAZ, FEP, } \\
\text { CI } \\
\text { P, LEV, ATM, } \\
\text { SXT }\end{array}$ & + \\
\hline EC792 & $\begin{array}{l}\text { Colorectal } \\
\text { surgery }\end{array}$ & Secretion & 52 & $\mathrm{M}$ & PcW & $\begin{array}{l}d f r A 17- \\
\text { aadA5 }\end{array}$ & $\mathrm{O} 25 \mathrm{~b}$ & B2 & $\begin{array}{l}\text { CTX, CAZ, FEP, } \\
\text { CIP, LEV, ATM, } \\
\text { SXT }\end{array}$ & \\
\hline EC913 & $\begin{array}{c}\text { Gastrointestinal } \\
\text { surgery }\end{array}$ & Urine & 52 & $\mathrm{~F}$ & PcW & $\begin{array}{l}d f r A 17- \\
\text { aadA5 }\end{array}$ & $\mathrm{O} 25 \mathrm{~b}$ & B2 & $\begin{array}{c}\text { CTX, CIP, LEV, } \\
\text { SXT }\end{array}$ & + \\
\hline EC934 & Hematology & Urine & 54 & $\mathrm{~F}$ & $\mathrm{PcW}$ & - & $\mathrm{O} 25 \mathrm{~b}$ & $\mathrm{~B} 2$ & SXT & \\
\hline EC935 & $\begin{array}{c}\text { Emergency } \\
\text { surgery }\end{array}$ & Secretion & 55 & $\mathrm{~F}$ & $\mathrm{PcW}$ & - & $\mathrm{O} 25 \mathrm{~b}$ & B2 & SXT & \\
\hline EC978 & Hematology & Blood & 43 & $\mathrm{~F}$ & $\mathrm{PcW}$ & $\begin{array}{l}d f r A 17- \\
\text { aadA5 }\end{array}$ & $\mathrm{O} 25 \mathrm{~b}$ & B2 & $\begin{array}{c}\text { CTX, CAZ, FEP, } \\
\text { CI } \\
\text { P, LEV, ATM, } \\
\text { SXT }\end{array}$ & + \\
\hline EC1044 & Hematology & Urine & 64 & $\mathrm{~F}$ & PcW & $\begin{array}{l}d f r A 17- \\
\text { aadA5 }\end{array}$ & $\mathrm{O} 25 \mathrm{~b}$ & B2 & $\begin{array}{c}\text { CTX, CAZ, FEP, } \\
\text { CI } \\
\text { P, LEV, ATM, } \\
\text { SXT }\end{array}$ & + \\
\hline
\end{tabular}


TABle 1: Continued.

\begin{tabular}{|c|c|c|c|c|c|c|c|c|c|c|}
\hline \multirow{2}{*}{ Isolates } & \multirow{2}{*}{ Ward } & \multirow{2}{*}{ Source } & \multirow{2}{*}{ Age } & \multirow{2}{*}{ Sex } & \multicolumn{2}{|c|}{$\begin{array}{l}\text { Genetic material in } \\
\text { isolate with integron }\end{array}$} & \multirow{2}{*}{ Serotype } & \multirow{2}{*}{$\begin{array}{l}\text { Phylogenetic } \\
\text { group }\end{array}$} & \multirow{2}{*}{$\begin{array}{l}\text { Resistance } \\
\text { proflies }\end{array}$} & \multirow{2}{*}{$\begin{array}{l}\text { Conjugation } \\
\text { experiments }\end{array}$} \\
\hline & & & & & Promoter & $\begin{array}{c}\text { Gene } \\
\text { cassette(s) }\end{array}$ & & & & \\
\hline EC1065 & Urinary surgery & Urine & 56 & M & PcW & $\begin{array}{l}\text { dfrA17- } \\
\text { aadA5 }\end{array}$ & $\mathrm{O} 25 \mathrm{~b}$ & B2 & SXT & \\
\hline EC1085 & Oncology & $\begin{array}{c}\text { Ascitic } \\
\text { fluid }\end{array}$ & 64 & $\mathrm{~F}$ & PcW & $\begin{array}{l}d f r A 17- \\
\operatorname{aadA5}\end{array}$ & $\mathrm{O} 25 \mathrm{~b}$ & B2 & $\begin{array}{c}\text { CTX, CAZ, FEP, } \\
\text { CI } \\
\text { P, LEV, ATM, } \\
\text { SXT }\end{array}$ & + \\
\hline EC1151 & Outpatient & Blood & 82 & M & $\mathrm{PcW}$ & $\begin{array}{l}\text { dfrA17- } \\
\text { aadA5 }\end{array}$ & $\mathrm{O} 25 \mathrm{~b}$ & B2 & $\begin{array}{l}\text { CTX, FEP, CIP, } \\
\text { LEV, ATM, SXT }\end{array}$ & \\
\hline
\end{tabular}

F, female; M, male; CTX, cefotaxime; CAZ, ceftazidime; FEP, cefepime; CIP, ciprofloxacin; LEV, levofloxacin; AK, amikacin; IPM, imipenem; TZP, piperacillin-tazobartan; ATM, aztreonam; SXT, trimethoprim-sulfamethoxazole; ETP, ertapenem, ${ }^{1-}$ : not detected, ${ }^{2+}$ : successfully transferred.

TABle 2: Size, number, and gene cassetes amplified from the variable region of integron in E.coli ST131.

\begin{tabular}{lcc}
\hline Approximate length $(\mathrm{kb})$ & Isolate $(n)$ & Gene cassette $(s)$ \\
\hline $0.15^{1}$ & 2 & - \\
1.6 & 4 & $d f r A 17$-aadA5 \\
$1.6+0.7^{2}$ & 12 & $d f r A 17$-aadA5 \\
3.0 & 1 & aac $\left(6^{\prime}\right)$-Ib-cr-cmlA5 \\
Total & 19 & \\
\hline
\end{tabular}

${ }^{1}$ The $0.15 \mathrm{~kb}$ amplicon was found to be a integron variable region without any gene cassette present but contained partial sequences of $5^{\prime}$ and $3^{\prime}$ conserved segments of integrons. ${ }^{2}$ The $0.7 \mathrm{~kb}$ amplicon was found to be a integron variable region without any gene cassette present.

3.4. Bacterial Clonal Relatedness. PFGE analysis of 22 integron-positive E. coli ST131 isolates revealed that these isolates were divided into 12 clusters (named A-L, in Figure 1) using $70 \%$ similarity cutoff value. Two clusters (A and $\mathrm{G})$ were frequent, containing 4 isolates, respectively.

PFGE analysis of the 83 E. coli ST131 isolates (integronpositive and -negative isolates) demonstrated these subtypes were grouped into 22 different PFGE clusters (named 1-22, in Supplementary Data) using 70\% similarity cutoff value. The integron-positive isolates were scattered in 10 groups. And 10/22 (45.5\%) of integron-positive isolates were clustered into the same clonal group (3).

\section{Discussion}

This study demonstrated the occurrence of integrons among E. coli ST131 clinical isolates. The results showed that the prevalence of integrons was low, and some were located on transferable plasmids. The prevalence of the integron $(26.5 \%)$ in this study was similar to that in our previous report $(26.7 \%)$ [18]; however, it is lower than that found in clinical Enterobacteriaceae isolates in China (59.9\%) [19]. The result suggested that the prevalence of integron was lower in E. coli ST131 as compared with other clinical isolates.

E. coli ST131 isolates showed high antimicrobial resistance to SXT, CIP, LEV, and CTX. In China, sulfonamides (such as SXT), $\beta$-lactams (such as CTX), and quinolones (such as CIP) are often used to cure E. coli infections; therefore, the high resistance of E. coli ST131 may be due to the frequent and inappropriate use of these antimicrobials [20-22].

Integrons are known to be correlated with multidrug resistance $(\mathrm{MDR})[23,24]$. Multiple antibiotic resistance rates of integron-positive and -negative strains were $45.5 \%$ and $13.3 \%$, respectively. This survey demonstrated MDR are widely distributed in E. coli ST131 (Table 1).

As previous studies reported, many antibiotic resistance gene cassettes in integrons probably play an important role in the development of antibiotics resistance $[2,25]$. In this study, integrons were significantly associated with SXT. Two different gene cassettes were detected (Table 2), which correlated with resistance to a variety of aminoglycosides ( $a a c$ and $a a d)$, chloramphenicol $(\mathrm{cmlA})$, and trimethoprim ( $\left.d f_{r} A 17\right)$, and the $d f r A 17$-aadA5 $(84.2 \%)$ gene cassette dominated in integron-positive isolates in this study, which may contributed to resistance to SXT. The gene cassettes identified were not novel in this study, and it was also the most prevalent gene cassette in E. coli in other previous studies [26, 27]. According to the database in GenBank, a novel cassette array, aac $\left(6^{\prime}\right)-I b-c r-c m l A 5$, was first reported in E. coli, suggesting the ability of integrons to capture and integrate resistance gene and to form novel cassettes that mediate resistance and multidrug resistance of E. coli ST131 clinical isolates. However, the aac $\left(6^{\prime}\right)-I b-c r-$ cmlA5-carrying isolate was found to be susceptible (or intermediate) to all antimicrobials (Table 1) which indicated that there may exist some unknown mechanism leading to this phenomenon.

We also explored the presence of antimicrobial resistance genes that played a significant role in antimicrobial resistance (Table 3 ). The bla $a_{\text {OXA-1 }}$ gene was found in 9 of 22 integron-positive isolates. This gene was often found as gene cassettes while not detected in variable region in this study $[28,29]$. The fact could be explained by the limitation of PCR or loss of $5^{\prime}$ and $3^{\prime}$ conserved segments of integrons. Regarding tet gene, the tet $A$ gene was the most common one in integron-positive isolates, supporting the previous reports highlighting that the tet $A$ gene was located on the same conjugative plasmid with integron [30]. In this study, the higher percentage of resistance to STX might be 
TABle 3: Genes of resistance detected among E.coli ST131 strains with and without integrons.

\begin{tabular}{|c|c|c|c|c|}
\hline \multirow{2}{*}{ Antibiotics } & \multicolumn{2}{|c|}{ Integron-positive strains $(n=22)$} & \multicolumn{2}{|c|}{ Integron-negative strains $(n=61)$} \\
\hline & No. of resistance isolates & Genes detected (no. of strains) & No. of resistance isolates & Genes detected (no. of strains) \\
\hline Ampicillin & $-^{*}$ & $\begin{array}{l}\text { bla }_{\text {TEM }}(11) \\
\text { bla }\end{array}$ & - & $\begin{array}{l}\text { bla }_{\text {TEM }}(23) \\
\text { bla }_{O X A-1}(1)\end{array}$ \\
\hline & - & $\begin{array}{l}\text { tetA }(1) \\
\text { tetC }(3)\end{array}$ & - & $\begin{array}{c}\text { tet } A(20) \\
\text { tetB }(2)\end{array}$ \\
\hline Tetracycline & & $\operatorname{tet} A+\operatorname{tet} B(6)$ & & tetC (8) \\
\hline & & $\operatorname{tet} A+\operatorname{tet} C(10)$ & & $\begin{array}{c}\operatorname{Tet} A+\operatorname{tet} C(10) \\
\operatorname{tet} B+\operatorname{tet} C(1)\end{array}$ \\
\hline & 21 & sul1 (15) & 35 & $\operatorname{sul1}(7)$ \\
\hline Sulphonamide & & sul2 (3) & & sul2 (5) \\
\hline & & sul1 + sul2 (3) & & sull + sul2 (20) \\
\hline Ciprofloxaci & 16 & $q n r B(2)$ & 43 & $q n r S(1)$ \\
\hline Streptomycin & - & $\operatorname{aadA}(2)$ & - & ND \\
\hline Kanamycin & - & ND & - & $\begin{array}{c}a p h A 1(1) \\
a p h A 1+a p h A 2(1)\end{array}$ \\
\hline Chloramphenicol & - & $\begin{array}{c}c m l A(1) \\
\text { clmA }+ \text { floR (1) }\end{array}$ & - & floR (2) \\
\hline
\end{tabular}

*Not detected; ND:no gene detected

TABLE 4: Association between antibiotic profile and integron in E. coli ST131.

\begin{tabular}{|c|c|c|c|c|c|c|c|c|c|c|}
\hline \multirow{3}{*}{ Antibiotic } & \multicolumn{9}{|c|}{ Antibiotic susceptibility } & \multirow{3}{*}{$p$ value } \\
\hline & \multicolumn{3}{|c|}{ All isolates $(n=83)$} & \multicolumn{3}{|c|}{$\begin{array}{l}\text { Integron-positive isolates } \\
\qquad(n=22)\end{array}$} & \multicolumn{3}{|c|}{$\begin{array}{l}\text { Integron-negative isolates } \\
\qquad(n=61)\end{array}$} & \\
\hline & $S(\%)$ & $I(\%)$ & $R(\%)$ & $S(\%)$ & $I(\%)$ & $R(\%)$ & $S(\%)$ & $I(\%)$ & $R(\%)$ & \\
\hline CTX & 25.3 & 3.6 & 71.1 & 31.8 & 0.0 & 68.2 & 23.0 & 4.9 & 72.1 & 0.726 \\
\hline CAZ & 49.4 & 24.1 & 26.5 & 54.5 & 9.1 & 36.4 & 47.5 & 29.5 & 23.0 & 0.222 \\
\hline FEP & 55.4 & 13.3 & 31.3 & 50.0 & 0.0 & 50.0 & 57.4 & 18.0 & 24.6 & 0.028 \\
\hline CIP & 28.9 & 1.2 & 69.9 & 27.3 & 4.5 & 68.2 & 29.5 & 0.0 & 70.5 & 0.840 \\
\hline LEV & 30.1 & 0.0 & 69.9 & 31.8 & 0.0 & 68.2 & 29.5 & 0.0 & 70.5 & 0.840 \\
\hline $\mathrm{AK}$ & 79.5 & 12.1 & 8.4 & 68.2 & 18.2 & 13.6 & 83.6 & 9.8 & 6.6 & 0.564 \\
\hline IPM & 96.4 & 0.0 & 3.6 & 100.0 & 0.0 & 0.0 & 95.1 & 0.0 & 4.9 & 0.562 \\
\hline TZP & 95.2 & 3.6 & 1.2 & 90.9 & 9.1 & 0.0 & 96.8 & 1.6 & 1.6 & 1.000 \\
\hline ATM & 37.4 & 26.5 & 36.1 & 50.0 & 4.5 & 45.5 & 32.8 & 34.4 & 32.8 & 0.289 \\
\hline SXT & 32.5 & 0.0 & 67.5 & 4.5 & 0.0 & 95.5 & 42.6 & 0.0 & 57.4 & 0.003 \\
\hline ETP & 98.8 & 1.2 & 0.0 & 100.0 & 0.0 & 0.0 & 98.4 & 1.6 & 0.0 & - \\
\hline
\end{tabular}

CTX, cefotaxime; CAZ, ceftazidime; FEP, cefepime; CIP, ciprofloxacin; LEV, levofloxacin; AK, amikacin; IPM, imipenem; TZP, piperacillin-tazobartan; ATM, aztreonam; SXT, trimethoprim-sulfamethoxazole; ETP, ertapenem.

attributed to the higher prevalence of sul gene among those integron-positive isolates, and this result corroborates a study reported previously that sul1 gene is usually encoded by class 1 integrons and is part of the $3^{\prime}$ conserved segment [31].

Additionally, similar to another previous study, PcW was the most frequent common promoter in clinical E. coli isolates in this study, a relatively weak promoter [32]. However, compared with another previous finding in other bacteria, only one promoter was detected in this study that was a strange phenomenon $[33,34]$. As discussed before, the prevalence of the promoter in E. coli ST131 and whether this is a feature of E. coli ST131 strains should be further investigated. Furthermore, the weaker Pc promoter showed the more efficient excision activity, which promotes integration of exogenous gene cassettes, and these suggested that PcW-carrying E. coli ST131 isolates have a strong capability to excise and capture gene cassettes, that might promote the spread of antimicrobial resistance [35].

In this study, 9 (52.9\%) E. coli ST131 isolates transferred integron and resistance gene cassettes to E. coli J53 $A z^{r}$ by conjugation. Many previous studies found that most of the resistance determination and integron in $E$. coli were encoded in a transferable plasmid, which might be horizontally transferred to the isolates among E. coli ST131 or different bacteria species by conjugation, potentially resulting in multiple drug resistance of bacteria [36, 37].

The result of PFGE demonstrated that integron-positive isolates were highly diverse in this study and there was no dominant clone (Figure 1). Interestingly, nearly half of integron-positive isoaltes belonged to the same group when we performed PFGE analysis on all isolates (Supplementary Data). Future study will be carried out to investigate this phenomenon. 


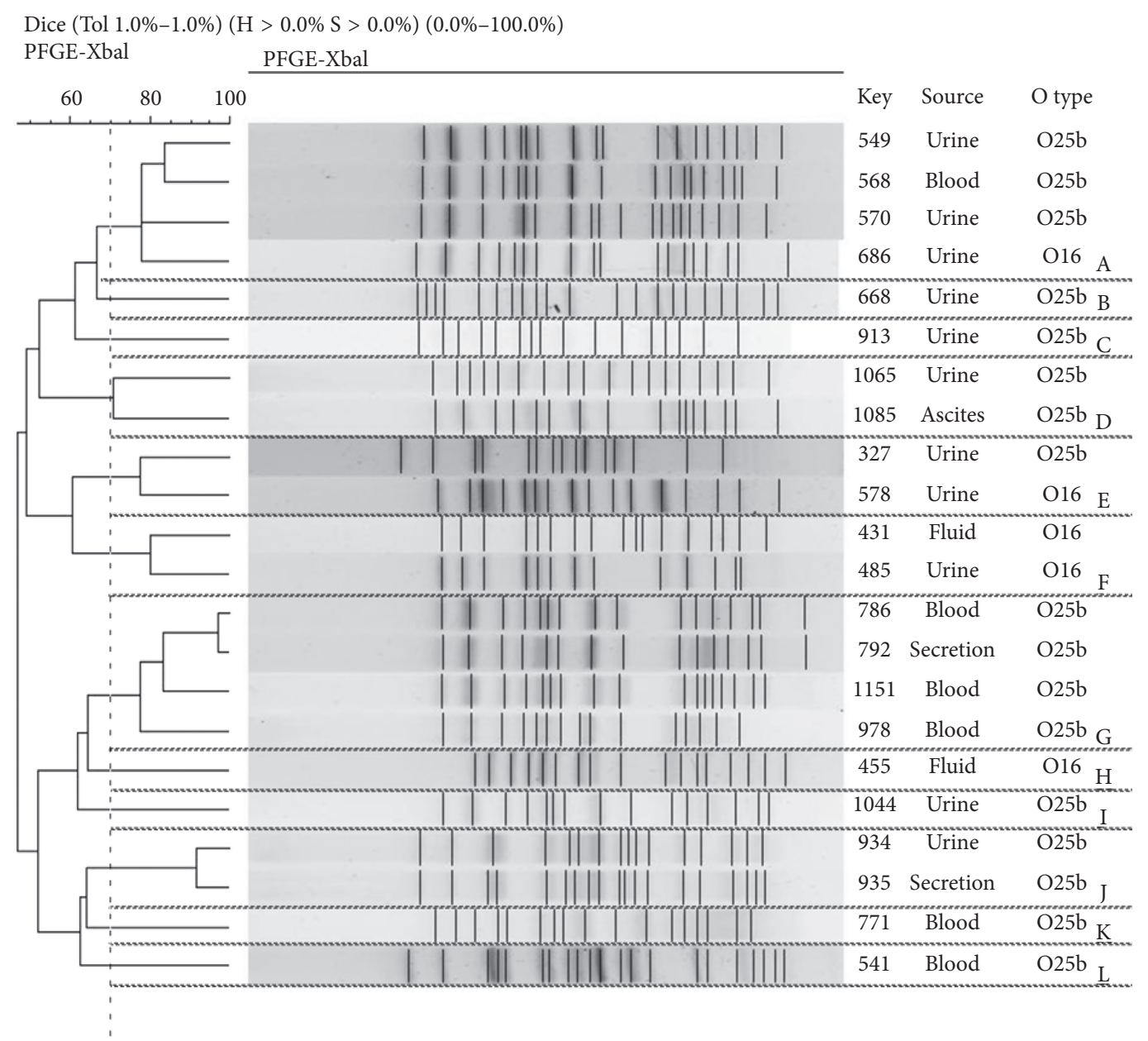

FIGURE 1: Dendrogram generated by bionumerics software that demonstrates the relationship of 22 integron-positive E. coli ST131 isolates at $70 \%$ similarity level, after digestion with XbaI. Strain designation, sample source, and O serotype are shown. The analysis of the bands generated was performed using the Dice coefficient and unweighted pair group method.

\section{Conclusions}

In conclusion, a low prevalence of integrons was detected in E. coli ST131 clinical isolates. Continued surveillance of this mobile genetic element should be performed to study the evolution of antibiotic resistance among E. coli ST131.

\section{Data Availability}

The data used to support the findings of this study are available from the corresponding author upon request.

\section{Conflicts of Interest}

No potential conflicts of interest relevant to this article were reported.

\section{Acknowledgments}

This study was supported by the Joint Funds for the Innovation of Science and Technology, Fujian Province (Grant number: 2017Y9049).

\section{Supplementary Materials}

Pulsed-field gel electrophoresis (PFGE) of XbaI-digested DNA from 83 ST131 E. coli isolates. Red box showed the 22 integron-positive ST131 E. coli isolates at a 70\% similarity level. Supplementary Materials (Supplementary Materials)

\section{References}

[1] M. Kaushik, S. Kumar, R. K. Kapoor, J. S. Virdi, and P. Gulati, "Integrons in enterobacteriaceae: diversity, distribution and epidemiology," International Journal of Antimicrobial Agents, vol. 51, no. 2, pp. 167-176, 2018.

[2] S. R. Partridge, S. M. Kwong, N. Firth, and S. O. Jensen, "Mobile genetic elements associated with antimicrobial resistance," Clinical Microbiology Reviews, vol. 31, no. 4, pp. 88-117, 2018.

[3] X. Yang, W. Zou, J. Zeng et al., "Prevalence of antimicrobial resistance and integron gene cassettes in, Escherichia coli, isolated from yaks (Poephagus grunniens) in aba Tibetan autonomous prefecture, China," Microbial Pathogenesis, vol. 111, pp. 274-279, 2017.

[4] T. Xu, J. Wang, J. Ying et al., "Characterisation of a class 1 integron associated with the formation of quadruple blaGES-5 
cassettes from an IncP-1 $\beta$ group plasmid in Pseudomonas aeruginosa," International Journal of Antimicrobial Agents, vol. 52, no. 4, pp. 485-491, 2018.

[5] N. Stoesser, A. E. Sheppard, G. Peirano et al., "First report ofblaIMP-14 on a plasmid harboring multiple drug resistance genes in Escherichia coli sequence type 131," Antimicrobial Agents and Chemotherapy, vol. 60, no. 8, pp. 5068-5071, 2016.

[6] C. M. Liu, M. Stegger, M. Aziz et al., "Escherichia coli ST131$\mathrm{H} 22$ as a foodborne uropathogen," mBio, vol. 9, no. 4, pp. $470-518,2018$.

[7] C. Rodrigues, E. Machado, S. Fernandes, L. Peixe, and $\hat{A}$. Novais, "Different Escherichia coli B2-ST131 clades (B and C) producing extended-spectrum $\beta$-lactamases (ESBL) colonizing residents of Portuguese nursing homes," Epidemiology and Infection, vol. 145, no. 15, pp. 3303-3306, 2017.

[8] B. Li, Y. Lu, F. Lan, Q. He, C. Li, and Y. Cao, "Prevalence and characteristics of ST131 clone among unselected clinical Escherichia coli in a Chinese University hospital," Antimicrobial Resistance \& Infection Control, vol. 6, no. 1, p. 118, 2017.

[9] A. Jouini, K. Ben Slama, L. Vinué et al., "Detection of Unrelated Escherichia coli strains harboring genes of CTX-M-15, OXA-1, and $A A C\left(6^{\prime}\right)-i b-C r$ enzymes in a Tunisian hospital and characterization of their integrons and virulence factors," Journal of Chemotherapy, vol. 22, no. 5, pp. 318-323, 2010.

[10] A. D. Khosravi, M. Motahar, and E. Abbasi Montazeri, "The frequency of class 1 and 2 integrons in Pseudomonas aeruginosa strains isolated from burn patients in a burn center of Ahvaz, Iran," PLoS One, vol. 12, no. 8, Article ID e0183061, 2017.

[11] B. Gu, M. Tong, W. Zhao et al., "Prevalence and characterization of class I integrons among Pseudomonas aeruginosa and Acinetobacter baumannii isolates from patients in Nanjing, China," Journal of Clinical Microbiology, vol. 45, no. 1, pp. 241-243, 2007.

[12] Clinical and Laboratory Standards Institute, Performance Standards for Antimicrobial Susceptibility Testing, Clinical and Laboratory Standards Institute, Wayne, PA, USA, 2016.

[13] Y. Saenz, L. Brinas, E. Dominguez et al., "Mechanisms of resistance in multiple-antibiotic-resistant Escherichia coli strains of human, animal, and food origins," Antimicrobial Agents and Chemotherapy, vol. 48, no. 10, pp. 3996-4001, 2004.

[14] M. E. Poey and M. Laviña, "Integrons in uropathogenic Escherichia coli and their relationship with phylogeny and virulence," Microbial Pathogenesis, vol. 77, pp. 73-77, 2014.

[15] C. Kehrenberg, S. Friederichs, A. D. Jong et al., "Identification of the plasmid-borne quinolone resistance gene qnrS in Salmonella enterica serovar Infantis," Journal of Antimicrobial Chemotherapy, vol. 58, no. 1, pp. 18-22, 2006.

[16] T. Yu, X. Jiang, Z. Wu, J. Wu, and Z. Wu, "Antimicrobial resistance, class 1 integrons, and horizontal transfer in Salmonella isolated from retail food in Henan, China," The Journal of Infection in Developing Countries, vol. 8, no. 6, pp. 705-711, 2014.

[17] B. Li, J.-Y. Sun, Q.-Z. Liu, L.-Z. Han, X.-H. Huang, and Y.-X. Ni, "High prevalence of CTX-M $\beta$-lactamases in faecal Escherichia coli strains from healthy humans in Fuzhou, China," Scandinavian Journal of Infectious Diseases, vol. 43, no. 3, pp. 170-174, 2011.

[18] B. Li, Z.-C. Zhao, M.-H. Wang, X.-H. Huang, Y.-H. Pan, and Y.-P. Cao, "Antimicrobial resistance and integrons of commensal Escherichia coli strains from healthy humans in China," Journal of Chemotherapy, vol. 26, no. 3, pp. 190-192, 2014.
[19] B. Gu, S. Pan, T. Zhao, Y. au, M. Mei, and P. Tong, "Novel cassette arrays of integrons in clinical strains of enterobacteriaceae in China," International Journal of Antimicrobial Agents, vol. 32, no. 6, pp. 529-533, 2008.

[20] H. Zhang, Q. Yang, K. Liao et al., "Update of incidence and antimicrobial susceptibility trends of Escherichia coli and Klebsiella pneumoniae isolates from Chinese intra-abdominal infection patients," BMC Infectious Diseases, vol. 17, no. 1, p. 776, 2017.

[21] W. Ma, J. Sun, S. Yang, and L. Zhang, "Epidemiological and clinical features for cefepime heteroresistant Escherichia coli infections in southwest China," European Journal of Clinical Microbiology \& Infectious Diseases, vol. 35, no. 4, pp. 571-578, 2016.

[22] F. Gao, P. Wang, H. Yang, Q. Miao, L. Ma, and G. Lu, "Recent developments of quinolone-based derivatives and their activities against Escherichia coli," European Journal of Medicinal Chemistry, vol. 157, pp. 1223-1248, 2018.

[23] H. Argüello, B. Guerra, I. Rodríguez, P. Rubio, and A. Carvajal, "Characterization of antimicrobial resistance determinants and class 1 and class 2 integrons in Salmonella enterica spp., multidrug-resistant isolates from pigs," Genes, vol. 9 , no. 5 , p. $256,2018$.

[24] C. Cheng, J. Sun, F. Zheng, W. Lu, Q. Yang, and Y. Rui, "New structures simultaneously harboring class 1 integron and ISCR1-linked resistance genes in multidrug-resistant gramnegative bacteria," BMC Microbiology, vol. 16, no. 1, p. 71, 2016.

[25] J.-H. Park, Y.-J. Kim, Binn-Kim, and K.-H. Seo, "Spread of multidrug-resistant Escherichia coli harboring integron via swine farm waste water treatment plant," Ecotoxicology and Environmental Safety, vol. 149, pp. 36-42, 2018.

[26] M. Sunde, G. S. Simonsen, J. S. Slettemeås, I. Böckerman, and M. Norström, "Integron, plasmid and host strain characteristics of Escherichia coli from humans and food included in the Norwegian antimicrobial resistance monitoring programs," PLoS One, vol. 10, no. 6, Article ID e0128797, 2015.

[27] T. Ali, S. Ur Rahman, L. Zhang et al., "ESBL-producing Escherichia coli from cows suffering mastitis in China contain clinical class 1 integrons with CTX-M linked to ISCR1," Frontiers in Microbiology, vol. 7, 2016.

[28] M. de Toro, Y. Sáenz, E. Cercenado et al., "Genetic characterization of the mechanisms of resistance to amoxicillin/ clavulanate and third-generation cephalosporins in Salmonella enterica from three Spanish hospitals," International Microbiology, vol. 14, no. 3, pp. 173-181, 2011.

[29] H. Yang, Y. Pan, L. Hu et al., "Antimicrobial resistance patterns and characterization of integrons in clinical isolates of shigella from China," Canadian Journal of Microbiology, vol. 60, no. 4, pp. 237-242, 2014.

[30] I. Chopra and M. Roberts, "Tetracycline antibiotics: mode of action, applications, molecular biology, and epidemiology of bacterial resistance," Microbiology and Molecular Biology Reviews, vol. 65, no. 2, pp. 232-260, 2001.

[31] D. Sandvang, D. J. M. Diggle, and D. J. Platt, "Translocation of integron-associated resistance in a natural system: acquisition of resistance determinants by inc $\mathrm{P}$ and inc W plasmids from Salmonella enterica typhimurium DT104," Microbial Drug Resistance, vol. 8, no. 3, pp. 151-160, 2002.

[32] L. Soufi, Y. Sáenz, L. Vinué, M. S. Abbassi, S. Hammami, and C. Torres, "Characterization of Pc promoter variants of class 1 integrons in Escherichia coli isolates from poultry meat," Foodborne Pathogens and Disease, vol. 10, no. 12, pp. 10751077, 2013. 
[33] C. S. Tseng, Y. C. Yen, C. C. Chang, and Y. M. Hsu, "Polymorphism of gene cassette promoter variants of class 1 integron harbored in S. Choleraesuis and typhimurium isolated from Taiwan," Biomedicine, vol. 4, no. 3, 2014.

[34] Q. Wei, X. Jiang, M. Li et al., "Diversity of gene cassette promoter variants of class 1 integrons in uropathogenic Escherichia coli," Current Microbiology, vol. 67, no. 5, pp. 543-549, 2013.

[35] L. Vinué, T. Jové, C. Torres, and M.-C. Ploy, "Diversity of class 1 integron gene cassette Pc promoter variants in clinical Escherichia coli strains and description of a new P2 promoter variant," International Journal of Antimicrobial Agents, vol. 38, no. 6, pp. 526-529, 2011.

[36] N. S. Singh, N. Singhal, and J. S. Virdi, "Genetic environment of blaTEM-1, blaCTX-M-15, blaCMY-42 and characterization of integrons of Escherichia coli isolated from an Indian urban aquatic environment," Frontiers in Microbiology, vol. 9, 2018.

[37] X. Xu, X. Li, M. Luo et al., "Molecular characterisations of integrons in clinical isolates of Klebsiella pneumoniae in a Chinese tertiary hospital," Microbial Pathogenesis, vol. 104, pp. 164-170, 2017. 